\title{
INFLUENCE OF COLUMNS OF SUPPORTED CONE ROOFS ON NATURAL FREQUENCIES OF STORED LIQUID
}

\author{
LYUBOMIR ZDRAVKOV* \\ University of Architecture, Civil Engineering and Geodesy, \\ 1 Hr. Smirnenski blvd., 1046, Sofia, Bulgaria \\ [Received: 04 January 2020. Accepted: 05 October 2020] \\ doi: 10.7546/JTAM.50.20.04.02
}

\begin{abstract}
Fluid, stored in tank, does not have behaviour of a solid during seismic impact. Hypothetically, the liquid response could be divided into two components - passive and active. Each of them has own natural frequencies. The standards have a various approach to determine the natural frequency of the active component. A common in all of them is that only liquid level-body radius ratio is taken into account. The possible presence of elements inside the tanks is not taken into account. A considerable number of tanks have cone roofs, supported by internal columns, which contact with the liquid. The question is, could we be able to follow the procedures described in the standards, for reservoirs with columns in the liquid?
\end{abstract}

KEY WORDS: stored liquid, internal columns, active part, natural frequencies.

\section{INTRODUCTION}

During seismic impact the stored in the tanks liquid does not behave as a solid. The response of liquid could be hypothetically divided into two components:

- passive (impulsive) - part of the liquid, close to the bottom, moves together with the tank as a solid. Its natural frequencies are the same as natural frequencies of the steel tank;

- active (convective) component (sloshing) - part of the liquid close to the upper surface moves freely and causes waves. This part of the liquid has its own natural frequencies that are different from the natural frequencies of the tank. The most important is the first form of sloshing.

The standards for design of steel tanks have various approaches for calculation of the natural frequency/period $T_{\text {conv }}$ of the active (convective) component of the liquid in the first form, for example:

A) according to EN1998-4 [1]

$$
T_{\text {conv }}=C_{c} \sqrt{r},
$$

${ }^{*}$ Corresponding author e-mail: zdravkov_fce@uacg.bg 
322 Influence of Columns of Supported Cone Roofs on Natural Frequencies of ...

where $T_{\text {conv }}$ is the period of active component of the liquid in first mode; $C_{c}$ - coefficient shown in Table 1; $r=D / 2$ - radius of the tank's shell; $D$ - diameter of the tank.

Table 1: Coefficients $C_{i}, C_{c}, m_{i}, m_{c}, h_{i}, h_{c}, h_{i}, h_{c}$

\begin{tabular}{ccccccccc}
\hline \hline$H_{t} / r$ & $\begin{array}{c}C_{i} \\
\left(\mathrm{~s} / \mathrm{m}^{1 / 2}\right)\end{array}$ & $C_{c},\left(\mathrm{~s} / \mathrm{m}^{0,5}\right)$ & $m_{i} / m$ & $m_{c} / m$ & $h_{i} / H_{t}$ & $h_{c} / H_{t}$ & $h_{i}^{\prime} / H_{t}$ & $h_{c}^{\prime} / H_{t}$ \\
\hline 0.3 & 9.28 & 2.09 & 0.176 & 0.824 & 0.400 & 0.521 & 2.640 & 3.414 \\
0.5 & 7.74 & 1.74 & 0.300 & 0.700 & 0.400 & 0.543 & 1.460 & 1.517 \\
0.7 & 6.97 & 1.60 & 0.414 & 0.586 & 0.401 & 0.571 & 1.009 & 1.011 \\
1.0 & 6.36 & 1.52 & 0.548 & 0.452 & 0.419 & 0.616 & 0.721 & 0.785 \\
1.5 & 6.06 & 1.48 & 0.686 & 0.314 & 0.439 & 0.690 & 0.555 & 0.734 \\
2.0 & 6.21 & 1.48 & 0.763 & 0.237 & 0.448 & 0.751 & 0.500 & 0.764 \\
2.5 & 6.56 & 1.48 & 0.810 & 0.190 & 0.452 & 0.794 & 0.480 & 0.796 \\
3.0 & 7.03 & 1.48 & 0.842 & 0.158 & 0.453 & 0.825 & 0.472 & 0.825 \\
\hline \hline
\end{tabular}

Written in Table $1 H_{t}$ is the distance from the bottom to the free surface of stored liquid.

B) according to API $650,12^{\text {th }}$ Edition [2]

$$
T_{\text {conv }}=1.81 k_{s} \sqrt{D},
$$

where $k_{s}$ is a coefficient that could be calculated through the expression:

$$
k_{s}=\frac{0.578}{\sqrt{\tanh \left(\frac{3.68 H_{t}}{D}\right)}} .
$$

Diameter of the tank $D$ and the maximum level $H_{t}$ of stored liquid in the formulae (2) and (3) should be in meters.

The equitation (2) is received after some modification and simplification of wellknown formula of Haroun [3]:

$$
T_{\mathrm{conv}}=\frac{2 \pi}{\omega_{s}}=\frac{2 \pi}{\sqrt{\frac{1.84 g}{r} \tanh \left(\frac{1.84 H_{t}}{r}\right)}},
$$

where $g=9.81 \mathrm{~m} / \mathrm{s}^{2}$ is the accepted value of gravity acceleration. 
C) according to EN14015:2004 [4]

Annex G, in which are mentioned the recommendations for seismic assurance of steel tanks, are copied by older versions of the American standard API650. The formula for calculation of $T_{\text {conv }}$ is the same as (2).

Knowing the value of the period $T_{\text {conv }}$, accounted by formulae (1-4), we can calculate easily the frequency $f$ of sloshing through the expression:

$$
f=\frac{1}{T_{\text {conv }}} .
$$

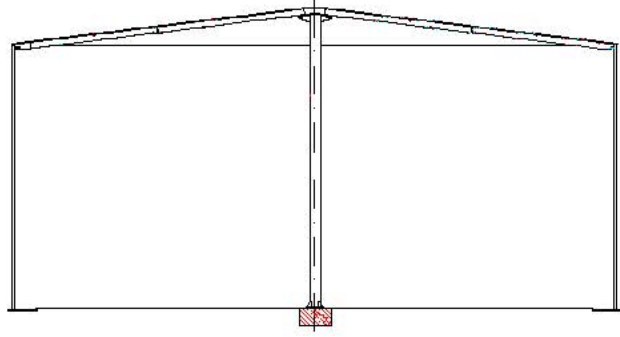

(a)

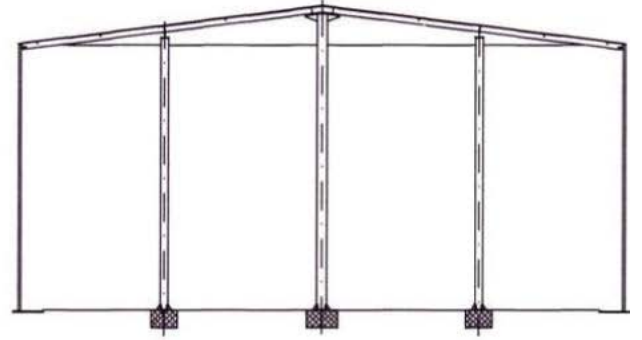

(b)

Fig. 1: Supported conical roof: (a) supported by one column; (b) supported by many columns.

The common thing for all above standards and formulae is that for calculation of the natural frequency of the active (convective) component of the fluid is considered only ratio $H_{t} / r$. It is not considered the possible presence of the elements inside the tank, which are obstacles for free moving of the stored liquid. At the same time many tanks have cone roofs, supported by internal columns. When the tanks have small dimensions, the column is only one, positioned in the centre, see Fig. 1a. When the facilities have big diameters, the columns are several and are placed in concentric circles, see Fig. $1 b$.

The presence of the columns in the liquid will inevitably influence the natural frequencies of the active (convective) component. The question is whether the change will be significant or not? Can we follow the above described formulae (1-4) and for the tanks with column in them or we shell look for another correlation? In this article the author will try to obtain answers of these questions.

\section{Modelling}

Several spatial models of the steel vertical cylindrical tanks with cone roofs are created, using the graphical interface Workbench of ANSYS [5]. Their volumes $V$, internal diameter $D$, height of the shell $H_{s}$, maximum filling $H_{t}$, number and thickness of 
324 Influence of Columns of Supported Cone Roofs on Natural Frequencies of ...

Table 2: Dimensions of modelled tanks

\begin{tabular}{cccccccc}
\hline \hline Tanks & $\begin{array}{c}\text { Volume } \\
V, \mathrm{~m}^{3}\end{array}$ & $\begin{array}{c}\text { Diameter } \\
D, \mathrm{~m}\end{array}$ & $\begin{array}{c}\text { Height } \\
H_{s}, \mathrm{~m}\end{array}$ & $\begin{array}{c}\text { Filling } \\
H_{t}, \mathrm{~m}\end{array}$ & $\begin{array}{c}\text { Number } \\
\text { courses }\end{array}$ & $\begin{array}{c}\text { Thickness, } \\
\mathrm{mm}\end{array}$ & $\begin{array}{c}\text { Type of } \\
\text { roof }\end{array}$ \\
\hline 1 & 1000 & 12.33 & 8.94 & 8.2 & $6 \times 1490$ & 4 & conical \\
2 & 2000 & 15.18 & 11.92 & 11.2 & $8 \times 1490$ & $6,5,5,4 \div 4$ & conical \\
3 & 3000 & 18.98 & 11.92 & 11.2 & $8 \times 1490$ & $7,6 \div 6$ & conical \\
4 & 5000 & 22.8 & 11.92 & 11.2 & $8 \times 1490$ & $9,8,7,6 \div 6$ & conical \\
\hline \hline
\end{tabular}

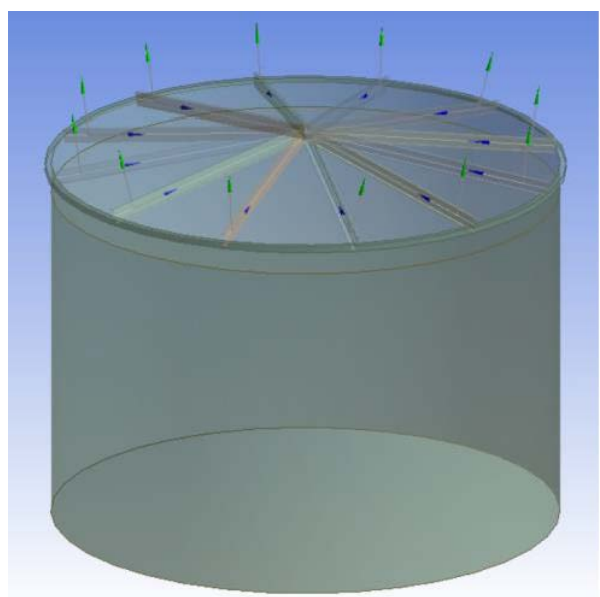

(a)

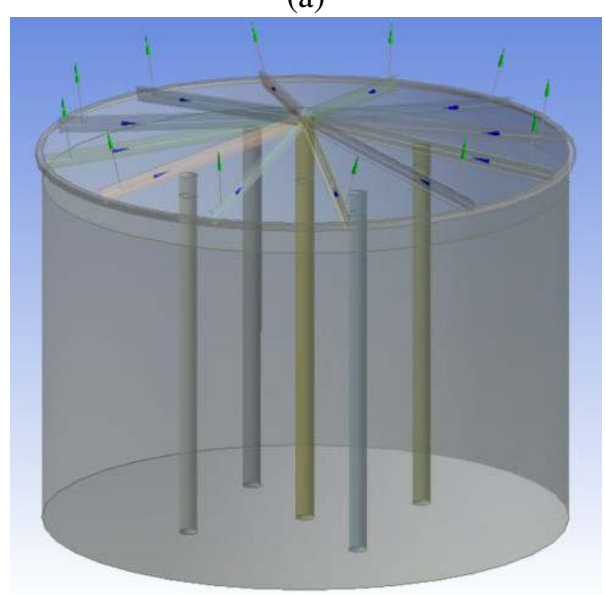

(c)

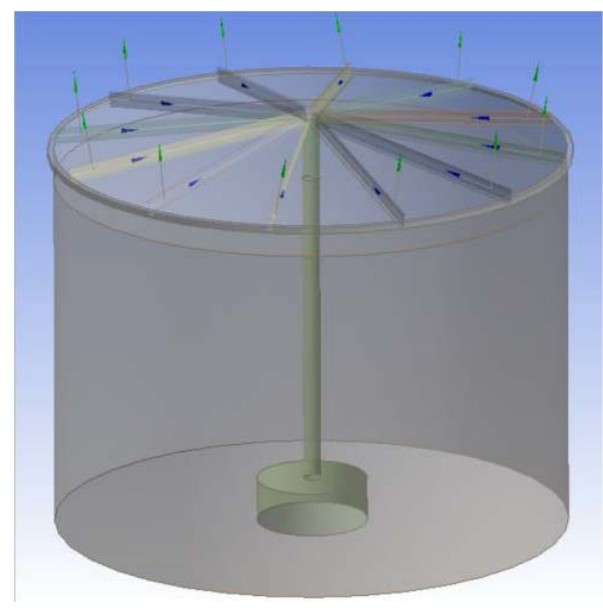

(b)

Fig. 2: Types of researched steel tanks: (a) self-supporting cone roof; (b) supported cone roof with one column; (c) supported cone roof with five columns. 
shell courses are according to the Standard working documentation of aboveground storage tanks [6], see Table 2.

The research is conducted for three types of tanks:

a) tanks with self-supporting conical roofs, i.e. without internal columns, see Fig. 2a;

b) tanks with one internal column, positioned in the centre of the tank;

c) tanks with five internal columns - one is placed in the centre and the other are positioned in circle around it, see Fig. 2c.

The columns have a section $\varnothing 426 \mathrm{~mm} \times 10 \mathrm{~mm}$. All of them are fixed to the base.

In the tank with one column, see Fig. 2b, steel cylindrical body exists, with diameter $\varnothing 2660 \mathrm{~mm}$ and height $1000 \mathrm{~mm}$ [6]. This body is filled with concrete and its purpose is:

- to distribute vertical loads from the roof on a bigger surface on the earth base;

- does not permit uplift of the roof by over pressure in the tank and/or wind loading.

The characteristics of the used materials are as follow:

a) steel: Young's modulus $-E=200,000 \mathrm{MPa}$; Poisson's ratio $-\nu=0.3$; density $-\rho_{s}=7850 \mathrm{~kg} / \mathrm{m}^{3}$.

b) water: sound speed in the water $-v_{w}=1,482.1 \mathrm{~m} / \mathrm{s}$; density $-\rho_{w}=998 \mathrm{~kg} / \mathrm{m}^{3}$; viscosity - not accounted.

Specific features of creation of numerical models are as follow:

a) module, used in ANSYS Workbench for determination of natural frequency of the liquid, is Modal Acoustics. In the previous research of the author [7] it was proved that this module is the unique that returns reliable results without use of the additional text commands;

b) steel body of the tank is simulated by shell elements;

c) body of the water is modelled through use of fluid elements;

d) workbench creates connection in an automatic between the two materials, which can have different characteristics. In the current research, it is accepted that the two materials can slide one to the other freely, but without separation. The mutual penetrating of the two materials is limited to $0.01 \mathrm{~mm}$;

e) the maximal dimension of the finite element of the mesh is limited to $500 \mathrm{~mm}$;

f) used elements have nodes only in the end edges, i.e. the middle nodes are deactivated;

g) tanks are fixed to the earth base;

h) on the upper edge of the shell of the tank is placed angular section, welded on a rib. It has section $150 \mathrm{~mm} \times 150 \mathrm{~mm}$ and thickness equal to the thickness of the last course; 
326 Influence of Columns of Supported Cone Roofs on Natural Frequencies of ...

i) roof's structure is simulated through a lot of radial frame elements, having a section according to the Standard working documentation of aboveground steel tanks [6]:

- tank with volume $V=1,000 \mathrm{~m}^{3}-12$ pcs. girders from U36 by BDS 6176-75;

- tank with volume $V=2,000 \mathrm{~m}^{3}-14$ pcs. girders from $\mathrm{I} 45$ by BDS 5951-75;

- tank with volume $V=3,000 \mathrm{~m}^{3}-18$ pcs. girders from I45 by BDS 5951-75;

- tank with volume $V=5,000 \mathrm{~m}^{3}-24$ pcs. girders from I50 by BDS 5951-75;

j) gravity acceleration $g=9.8066 \mathrm{~m} / \mathrm{s}^{2}$;

k) effects from damping of the liquid are not accounted.

\section{RESUlTS}

First two modes of sloshing of the free surface of water are accounted in the three variants of roof's structure. Theoretically, they have values on Fig. 3 type:

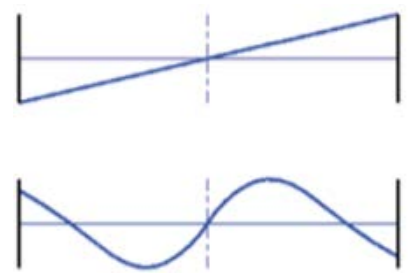

Mode 1

Mode 2

Fig. 3: Theoretical shape of the free surface of the liquid for the first two sloshing modes.

For verification of the correctness of numerical modelling, the natural frequencies of the researched tanks without internal columns are calculated according to the suggestions of other known researchers in this field, as:

A) $L a m b$

The first two natural frequencies are calculated through the expression [8]:

$$
f_{i}=\frac{1}{2 \pi} \sqrt{\alpha_{i} \frac{g}{r} \tanh \left(\alpha_{i} \frac{H_{t}}{r}\right)},
$$

where $\alpha_{i}$ is a coefficient, having the following values: $0.586 \pi-$ for the first mode; $1.697 \pi$ - for the second mode; 
B) Housner

According to him, the period of first natural mode of wave sloshing is calculated according to the formula [9]:

$$
T_{\text {conv }}=2 \pi \sqrt{\frac{M_{1}}{k_{1}}},
$$

where

$$
\begin{gathered}
M_{1}=0.6 M \frac{r}{1.8 H_{t}} \tanh \left(\frac{1.8 H_{t}}{r}\right), \\
k_{1}=5.4 \frac{M_{1}^{2}}{M} \frac{g H_{t}}{r^{2}},
\end{gathered}
$$

in which

$$
M=V \rho,
$$

where $V$ is the volume of the stored liquid $\left[\mathrm{m}^{3}\right] ; \rho-$ the density of the liquid $\left[\mathrm{t} / \mathrm{m}^{3}\right]$.

\section{C) Haroun}

The period of the first natural mode of the wave sloshing is calculated according to (4). At this place the author will point again that the standards API 650 and EN14015:2004 use the modified version of the formula (4).

The accounted values of natural frequencies of the wave sloshing are shown in Tables 3-6.

Table 3: Natural frequencies (in $\mathrm{Hz}$ ) of free surface of the liquid in tank with volume of $1,000 \mathrm{~m}^{3}, \mathrm{~Hz}$

\begin{tabular}{cccccccccc}
\hline \hline & \multicolumn{3}{c}{ ANSYS } & & EN1998-4 & Lamb & Housner & Haroun \\
\cline { 2 - 4 } \cline { 6 - 9 } Mode & $\begin{array}{c}\text { Without } \\
\text { columns }\end{array}$ & $\begin{array}{c}\text { with 1 } \\
\text { column }\end{array}$ & $\begin{array}{c}\text { with 5 } \\
\text { columns }\end{array}$ & & \multicolumn{3}{c}{ Without internal columns } \\
\hline \multirow{2}{*}{1} & 0.2706 & 0.2704 & 0.2695 & & 0.27 & 0.2703 & 0.2671 & 0.2702 \\
2 & 0.4655 & 0.4683 & 0.4641 & & - & 0.4635 & - & - \\
\hline \hline
\end{tabular}


328 Influence of Columns of Supported Cone Roofs on Natural Frequencies of ...

Table 4: Natural frequencies (in $\mathrm{Hz}$ ) of free surface of the liquid in tank with volume of $2,000 \mathrm{~m}^{3}, \mathrm{~Hz}$

\begin{tabular}{cccccccccc}
\hline \hline & \multicolumn{3}{c}{ ANSYS } & & & EN1998-4 & Lamb & Housner & Haroun \\
\cline { 2 - 4 } \cline { 6 - 8 } Mode & Without & with 1 & with 5 & & & Without internal columns & \\
& columns & column & columns & & & 0.2444 & 0.2415 & 0.2443 \\
1 & 0.2446 & 0.2448 & 0.2441 & & 0.245 & 0.247 & - & - \\
\hline \hline
\end{tabular}

Table 5: Natural frequencies (in $\mathrm{Hz}$ ) of free surface of the liquid in tank with volume of $3,000 \mathrm{~m}^{3}, \mathrm{~Hz}$

\begin{tabular}{|c|c|c|c|c|c|c|c|}
\hline \multirow[b]{2}{*}{ Mode } & \multicolumn{3}{|c|}{ ANSYS } & EN1998-4 & Lamb & Housner & Haroun \\
\hline & $\begin{array}{l}\text { Without } \\
\text { columns }\end{array}$ & $\begin{array}{c}\text { with } 1 \\
\text { column }\end{array}$ & $\begin{array}{c}\text { with } 5 \\
\text { columns }\end{array}$ & \multicolumn{4}{|c|}{ Without internal columns } \\
\hline 1 & 0.2168 & 0.2167 & 0.2165 & 0.215 & 0.2132 & 0.214 & 0.2166 \\
\hline 2 & 0.3744 & 0.3754 & 0.3737 & - & 0.3675 & - & - \\
\hline
\end{tabular}

Table 6: Natural frequencies (in $\mathrm{Hz}$ ) of free surface of the liquid in tank with volume of $5,000 \mathrm{~m}^{3}, \mathrm{~Hz}$

\begin{tabular}{ccccccccc}
\hline \hline & \multicolumn{3}{c}{ ANSYS } & & EN1998-4 & Lamb & Housner & Haroun \\
\cline { 2 - 4 } \cline { 6 - 9 } Mode & $\begin{array}{c}\text { Without } \\
\text { columns }\end{array}$ & $\begin{array}{c}\text { with 1 } \\
\text { column }\end{array}$ & $\begin{array}{c}\text { with 5 } \\
\text { columns }\end{array}$ & & \multicolumn{3}{c}{ Without internal columns } \\
& 0.1950 & 0.1949 & 0.1948 & & 0.1942 & 0.195 & 0.1924 & 0.1949 \\
1 & 0.3414 & 0.3415 & 0.3411 & & - & 0.3408 & - & - \\
\hline
\end{tabular}

\section{CONCLUSIONS}

The values of the natural frequencies of the free surface of the liquid, calculated through the module Modal Acoustics of ANSYS Workbench, are very close to the theoretically determined ones. Accounted differences between numerical analysis and proposed by Lamb, Housner and Haroun analytical systems equations are less than $2 \%$.

Accounted differences between natural frequencies of the free surface of the liquid in the tanks with internal columns and tanks without internal columns are very 
small, less than $1 \%$. The conclusion is the methodology for cylindrical bodies without columns in them can be used also for tanks with supported cone roofs with a small error.

\section{REFERENCES}

[1] EN 1998-4:2006. Eurocode 8: Design of structures for earthquake resistance. Part 4: Silos, tanks and pipelines. European Committee for Standardization, Brussels, 2006.

[2] API Std. 650, Welded Steel Tanks for Oil Storage, Twelfth Edition, Addendum 3. American Petroleum Institute, Washington. August 2018.

[3] M.A. Haroun (1983) Vibration studies and test of liquid storage tanks. Earthquake Engineering and Structural Dynamics 11 179-206.

[4] EN 14015:2004, Specification for the design and manufacture of site built, vertical, cylindrical, flat-bottomed, above ground, welded, steel tanks for the storage of liquids at ambient temperature and above. European Committee for Standardization, Brussels, November 2004.

[5] ANSYS ${ }^{\circledR}$ v.19 Documentation. ANSYS Inc., Canonsburg, PA, the USA.

[6] Standard working documentation of aboveground storage tanks with $100 \mathrm{~m}^{3} \times$ 10, $000 \mathrm{~m}^{3}$ capacity, built by roll method. MCCM, 1977.

[7] M. PantusheVA, L. ZdRAVKov (2019) Numerical analysis of vertical steel storage tanks in ANSYS Workbench and ANSYS Mechanical APDL. Annual of the University of Architecture, Civil Engineering and Geodesy, Sofia 52(3) 851-865.

[8] H. LAMB (1932) "Hydrodynamics". Cambridge University Press, UK.

[9] G.W. Housner (1963) The dynamic behaviour of water tanks. Bulletin of Seismological Society of America 53 381-387. 